\section{Development and Characterization of Genic Microsatellites for the Ornamental Plant Green and Gold (Chrysogonum virginianum)}

\author{
Marcin Nowicki ${ }^{1}$ \\ Department of Entomology and Plant Pathology, The University of \\ Tennessee, 2505 E J Chapman Drive, 370 Plant Biotechnology Building, \\ Knoxville, TN 37996-4560
}

Edward E. Schilling

Department of Ecology and Evolutionary Biology, The University of Tennessee, 569 Dabney Hall, 1416 Circle Drive, Knoxville, TN 37996

Sarah L. Boggess, Logan C. Houston, Matthew L. Huff, and Margaret E. Staton

Department of Entomology and Plant Pathology, The University of Tennessee, 2505 E J Chapman Drive, 370 Plant Biotechnology Building, Knoxville, TN 37996-4560

Jayne A. Lampley

Department of Ecology and Evolutionary Biology, The University of Tennessee, 569 Dabney Hall, 1416 Circle Drive, Knoxville, TN 37996

Robert N. Trigiano

Department of Entomology and Plant Pathology, The University of Tennessee, 2505 E J Chapman Drive, 370 Plant Biotechnology Building, Knoxville, TN 37996-4560

Additional index words. subspecies delimitation, genic SSR, population genetics

\begin{abstract}
The genus Chrysogonum is native to the eastern United States. Three entities have been recognized - either as three varieties of Chrysogonum virginianum or as two species, one of them with two varieties. The current study suggests that a fourth entity should be recognized. Several forms of the complex are in commercial trade as ornamentals. As very limited molecular information on Chrysogonum is available, we developed a set of genic simple sequence repeat markers (eSSRs) from de novo transcriptome sequencing. We tested a set of 17 eSSRs on a collection of $C$. virginianum genomic DNA samples from the three botanical varieties, and a new putative type observed in Tennessee, dubbed "Ocoee-type" for its geographic origin. The polymerase chain reaction and capillary electrophoresis analyses with downstream population genetics tools verified the usefulness of the eSSRs. By applying this approach, we showed recognizable variation within Chrysogonum, although it did not correspond exactly to previous infraspecific classifications. Finally, as demonstrated for the commercial cultivar Pierre included in the study, the eSSRs can be used for enhancing the future breeding or hybridization efforts of this ornamental plant.
\end{abstract}

\footnotetext{
Received for publication 6 Nov. 2018. Accepted for publication 10 Dec. 2018.

This study was funded fully by an Agricultural Research Service-U.S. Department of Agriculture grant $(58-6062-6)$ to the Trigiano laboratory for ornamental plants research. The funder had no role in study design, data collection and analysis, decision to publish, or preparation of the manuscript. Use of trade names is for identification purposes only and does not imply their endorsement by the authors or the study funding entities. The authors are grateful to the plant material collectors and herbaria for making them available to this study. The RNA sequencing raw read files are available as National Center for Biotechnology Information Sequence Read Archive accession SRR8181940.

${ }^{1}$ Corresponding author. E-mail: mnowicki@utk.edu
}

range; var. brevistolon is of intermediate plant height, has stolons of medium length, has both leafy and leafless flowering stems, and occurs in the middle portion of the generic range (Nesom, 2001; Stuessy, 1973, 1977). The relationships and generic limits of Chrysogonum have been a source of controversy, as has the circumscription of taxa within the genus (Gray, 1882; Nesom, 2001; Stuessy, 1973, 1977). An alternative taxonomy of the genus was proposed (Weakley, 2015); it recognized the "australe" entity at specific rank, presumably because of its allopatry and distinct morphology, in contrast to previous categorization that overlooked that fact (Nesom, 2001). Issues with subtribal relationships were resolved with molecular phylogenetic data, starting with the studies based on enzymatic restriction of the chloroplast genome that explored the phylogenetic position of Chrysogonum in the Heliantheae tribe (Panero and Jansen, 1997; Panero et al., 1999). Sequence-based studies analyzing the nuclear ribosomal sequences of the internal transcribed spacer and the external transcribed spacer provided support for removal of all but one of the classically recognized species of Chrysogonum and placement of the genus Chrysogonum in subtribe Engelmanniinae, together with Silphium L. and four other small genera (Clevinger and Panero, 2000). The genome sequence of $C$. virginianum has not been reported, and before this study only 14 sequences were available in the National Center for Biotechnology Information GenBank for the species. The species ploidy is assumed to be diploid $(2 \mathrm{~N}=2 \times=32$; Nesom, 2001; Solbrig et al., 1972), although some authors suggested it is tetraploid, based on the relatively high base chromosome number (Stuessy, 1973). Only scant phytopathological information is available on Green and Gold and includes a recent report on powdery mildew (Golovinomyces spadiceus; Trigiano et al., 2018a) and aerial blight (Sclerotinia sclerotiorum; Trigiano et al., 2018b). Green and Gold is used as a home garden ornamental plant in shady, moist areas with several cultivars of all three taxa available commercially, and some of them recognized by patents (Hawks, 2008; Hoffman et al., 2005). At the basal part of Green and Gold diaspores, there is an elaiosome, a fleshy, oilbearing structure. Ants foraging on the elaiosomes contribute to the plant dispersal (Gaddy, 1986; Nesom, 1978). The plant flowering time was used as a marker of global climate change in the Washington, DC area and was confirmed to advance by $31 \mathrm{~d}$ over 30 years of studies, ranking it as the fifth most altered among the 89 plant species investigated (Abu-Asab et al., 2001).

Among the neutral molecular markers, the microsatellites or simple sequence repeats (SSRs) are often used for population genetics and (sub)species delimitation (Duminil and Di Michele, 2009; Dupuis et al., 2012; Esfandani Bozchaloyi et al., 2017; Meudt et al., 2009). Compared with the genomic SSRs (gSSRs) developed on the nuclear DNA sequences, the eSSRs are developed 
from the assembled transcriptomes (Ellis and Burke, 2007; Varshney et al., 2005). eSSRs have become an attractive and efficient highthroughput molecular tool owing to comparatively lower cost for their development from species lacking sequenced genomes. The eSSRs conserved in the transcriptomes usually display somewhat lower diversity indices and higher conservation across taxa than gSSRs (Ellis and Burke, 2007; Eujayl et al., 2001; Varshney et al., 2002).

To better substantiate the current taxonomic subspecies delineation in the complex $C$. virginianum, we developed eSSRs based on de novo RNA sequencing (RNAseq). We selected 17 eSSRs and assessed their utility using a collection of 32 genomic DNA (gDNA) samples from the three currently recognized $C$. virginianum varieties from the eastern United States and a recentlydiscovered putative new form ("Ocoee-type") first observed in eastern Tennessee. Our survey of Chrysogonum also included a sample of the commercial cultivar Pierre, whose varietal attribution was not described. The purpose of this report was to present the results of the Chrysogonum eSSR development and the initial results on variability within the genus.

\section{Materials and Methods}

Plant materials and nucleic acids extraction. Samples of $C$. virginianum were obtained to represent a variety of locations from throughout its range in the southeastern United States. Sources included herbarium specimens collected between 1967 and 2003 and living material collected 2016 through 2018. The samples $(\mathrm{n}=31)$ belonged to the three currently recognized varieties assigned following Nesom (2001) and the newly observed putative "Ocoee-type" (Ocoee and Hiawassee River Valley samples, Tennessee). The "Ocoeetype" is distinct in having a tapering, cuneate leaf base similar to var. australe but lacking its distinctive long stolons. gDNA was isolated from dried leaves (herbarium specimens) or fresh leaf material (Table 1) using the DNA Plant Mini Kit (Qiagen, Germantown, MD), according to the manufacturer's protocol. A single leaf sample from a home garden (a morphologically typical $C$. virginianum of the "Ocoee-type," collected and transplanted from the Hiawassee River Valley, TN; 'Chry_2', Maryville, TN, collected 2018 and stored on dry ice) was also included. The gDNA of this sample was isolated from leaf tissue using the DNA Plant Mini Kit (Qiagen) according to the manufacturer's protocol. A leaf sample of the same living plant was also processed for total RNA using the Ribospin II kit (GeneAll Biotechnology, Seoul, Korea) as per the manufacturer's protocol.

De novo sequencing and development of eSSR markers. The RNA of $C$. virginianum specimen 'Chry_2' was submitted for Illumina MiSeq [pair-end $2 \times 250$ base pairs (bp)] sequencing (GeneWiz, South Plainfield, NJ). RNAseq data for C. virginianum

Table 1. Chrysogonum virginianum collections included in the study. ${ }^{\mathrm{z}}$

\begin{tabular}{|c|c|c|c|c|}
\hline DNA\# & C. virginianum var. & Collector and voucher details & Location & Yr collected \\
\hline 3511 & brevistolon & Bailey \& McCoy & Scott Co., TN & 2003 \\
\hline 4027 & australe & Rogers 2058-A & Forrest Co., MS & 1969 \\
\hline 4028 & brevistolon & McNeilus 00-489 & Shenandoah Co., VA & 2000 \\
\hline 4029 & australe & Rogers 9437-A & Wayne Co., MS & 1974 \\
\hline 4033 & virginianum & Filipczak 161 & Alamance Co., NC & 1980 \\
\hline 4036 & brevistolon & Panero 695 & Scott Co., TN & 1987 \\
\hline 4038 & brevistolon & Schell s.n. & Greene Co., TN & 1994 \\
\hline 4039 & brevistolon & Gaylon \& Schnabel 40873 & Claiborne Co., TN & 1967 \\
\hline 4500 & Ocoee-type & Floden et al., 2879 & Polk Co., TN & 2016 \\
\hline 4501 & Ocoee-type & Floden et al., 2880 & Polk Co., TN & 2016 \\
\hline 4502 & Ocoee-type & Floden et al., 2881 & Polk Co., TN & 2016 \\
\hline 4580 & brevistolon & Schilling 95-1 & $*$ & 2016 \\
\hline 4581 & Ocoee-type & Schilling 16-05 & Modoc Co., SC & 2016 \\
\hline 4582 & virginianum & Schilling DS1 & Chatham Co., NC & 2016 \\
\hline 4583 & virginianum & Schilling DS2 & Wake Co., NC & 2016 \\
\hline 4586 & Ocoee-type & Diggs s.n. & Oakwood Co., GA & 2016 \\
\hline 4605 & brevistolon & Floden \& Schilling 3046 & Hancock Co., TN & 2016 \\
\hline 4608 & brevistolon & Floden \& Schilling 3046 & Hancock Co., TN & 2016 \\
\hline 4609 & brevistolon & Floden \& Schilling 3181 & Clairborne Co., TN & 2016 \\
\hline 4624 & australe & Garden plant & * & 2016 \\
\hline 4631 & virginianum & Schilling A1 & Montgomery Co., NC & 2016 \\
\hline 4632 & virginianum & Schilling B1 & Montgomery Co., NC & 2016 \\
\hline 4633 & virginianum & Schilling A2 & Montgomery Co., NC & 2016 \\
\hline 4634 & virginianum & Schilling B2 & Montgomery Co., NC & 2016 \\
\hline 4650 & Ocoee-type & Datillo s.n. & Polk Co., TN & 2016 \\
\hline 4768 & australe & McDonald 5864 (MO) & Houston Co., AL & 1967 \\
\hline 4769 & australe & Kral 54955 (MO) & Antaga Co., AL & 1975 \\
\hline 4770 & Ocoee-type & Kral 64940 (MO) & McDuffie Co., GA & 1980 \\
\hline 4771 & Ocoee-type & Kral 64940 & Dawson Co., GA & 1976 \\
\hline 4772 & Ocoee-type & Kral 57573 & Lumpkin Co., GA & 1976 \\
\hline Chry_2 & Ocoee-type & Garden plant & Blount Co., TN & 2018 \\
\hline Pierre & virginianum & Commercial source & * & 2018 \\
\hline
\end{tabular}

${ }^{\mathrm{z} D N A \# ~ c o l u m n ~ m a r k s ~ t h e ~ l a b o r a t o r y ~ g e n o m i c ~ D N A ~ s a m p l e ~ c o d e . ~ V a r i e t y ~ w a s ~ e s t a b l i s h e d ~ f o l l o w i n g ~}$ Nesom (2001). Herbarium voucher details, sample location information $\left(^{*}\right.$; garden plant of unknown origin), and year of collection are listed. Individuals 'Chry_2' (serving for RNA extraction and RNA sequencing) and commercial cultivar Pierre are in bold.

produced were assessed for read quality using the quality control program FastQC, which identifies base content, sequence quality, and sequence duplication in fastq files of interest (Andrews, 2014). Adapter content was removed using the trimming program Skewer (Jiang et al., 2014) (minimum length: $30 \mathrm{bp}$, defaults used for all other parameters). To enable microsatellite identification, reads were assembled using Assembly By Short Sequences (ABySS), specifically its pairedend option, abyss-pe, using a k-mer size of 81 and default settings for all other options (Simpson et al., 2009). Low-complexity regions of the transcriptome were masked out with Dustmasker, with a level of 1 , before finding SSRs within the assembly (Morgulis et al., 2006). This study used a custom perl script to identify SSRs and call primers with Primer3 (Staton and Ficklin, 2018; Untergasser et al., 2012). This script searched for di-, tri-, and tetra-repeating motifs with an amplified fragment range of 100 to 250 bases.

eSSR screening and plant gDNA collection genotyping. From the developed eSSRs, we initially screened a pool of 50 primer pairs (20 of di-, 20 of tri-, and 10 of tetra-motif repeats) on the gDNA sample whose leaf was also used for RNA isolation and sequencing ('Chry_2'). The polymerase chain reaction (PCR) reaction volume was $10 \mu \mathrm{L}$ and included $5 \mu \mathrm{L}$ of $2 \times$ AccuStart II PCR SuperMix (Quanta BioSciences, Inc., Beverly, $\mathrm{MA}), 0.25 \mu \mathrm{M}$ of each primer, and $4 \mathrm{ng}$ of
gDNA. The PCR thermal profile used was as follows: initial denaturation at $94{ }^{\circ} \mathrm{C}$ for $4 \mathrm{~min}, 10$ touch-down cycles $\left(94{ }^{\circ} \mathrm{C}\right.$ for $20 \mathrm{~s}, 65{ }^{\circ} \mathrm{C}-1.0^{\circ} \mathrm{C}$ per cycle for $20 \mathrm{~s}, 72{ }^{\circ} \mathrm{C}$ for $30 \mathrm{~s}), 30$ cycles $\left(94^{\circ} \mathrm{C}\right.$ for $20 \mathrm{~s}, 55^{\circ} \mathrm{C}$ for $20 \mathrm{~s}, 72{ }^{\circ} \mathrm{C}$ for $30 \mathrm{~s}$ ), and final extension at $72{ }^{\circ} \mathrm{C}$ for $5 \mathrm{~min}$. The PCR products were visualized using capillary electrophoresis (QIAxcel Advanced Electrophoresis System; Qiagen) and analyzed using a 25 to $500 \mathrm{bp}$ DNA size marker and an internal 15/600 bp alignment marker. The 17 best-performing eSSRs (four di-, eight tri, and five tetra-motif repeats) based on agreement with the predicted size and one or two unambiguous alleles, were selected and used for genotyping of the $C$. virginianum gDNA collection. The resultant dataset was binned into allelic classes using FlexiBin (an MSExcel macro; Amos et al., 2007).

Estimation of the hierarchical fixation indices and population structure. The binned dataset was analyzed for an array of population genetics parameters. To estimate the basic indices, including number of alleles per locus, observed and expected heterozygosity, evenness, Shannon's diversity index, and allelic richness (defined as the number of alleles divided by the number of samples without missing data at that locus), we used the following packages: poppr (Kamvar et al., 2014, 2015), hierfstat (Goudet, 2005; Goudet et al., 1996), and strataG (Archer et al., 2017) in $\mathrm{R}$ version 3.4.3 (The R Core 
Team, 2014). Gene flow ( $\mathrm{Nm}$ ) was estimated using GenAlEx version 6.503 (Peakall and Smouse, 2012). The package poppr in $\mathrm{R}$ was used for calculations of the (pairwise) linkage disequilibrium. Discriminant Analysis of Principal Components (DAPC) was performed in $\mathrm{R}$ using the package adegenet version 2.1.1 (Jombart et al., 2010, 2018) and included cross-check and optimization by 1000 permutations over principal components number ranging from 1 to 32 .

\section{Results and Discussion}

C. virginianum transcriptome and eSSR development and screening. After preprocessing the RNAseq data through Skewer, $7,054,370$ of the initial 7,145,419 read pairs were available for further analysis; of these, 991,875 were trimmed using Skewer, and $6,062,495$ did not require trimming. The assembly generated by running ABySS on these remaining reads contained 841,375 scaffolds. A total of 4940 SSRs with primers were identified from the C. virginianum assembled transcriptome; of these, 3162 were dinucleotide repeats, 995 were trinucleotide repeats, and 783 were tetranucleotide repeats. All unique di-repeat SSR types were discovered. Similarly, of 60 unique tri-repeat SSRs, only $[\mathrm{AGT}]_{\mathrm{n}}$-types (and their redundant iterations) were missing in the assembled transcriptome of $C$. virginianum. From among the total of 252 unique tetra-SSRs, only 118 were discovered in the assembled transcriptome of $C$. virginianum with at least one SSR present. The number of SSRs that yielded primers as per our algorithm corresponded with their respective counts of SSRs discovered in the assembled transcriptome, regarded both in the repeat-length fashion, or repeat-motif (Fig. 1). Similar to other studies (Arias et al., 2011), the most frequent SSRs were di-repeats with $[\mathrm{GC}]_{\mathrm{n}}$ ranking the lowest among them. In contrast to other Asteraceae plants (Peng et al., 2014), the tetra-repeat SSRs occurred almost as frequently as the tri-repeat SSRs and were among the most frequently discovered in the unique motif manner.

C. virginianum eSSR characteristics and varietal distances. Based on the genotyping dataset accrued, the used eSSRs are well dispersed over the $C$. virginianum genome (Fig. 2A). The small range of pairwise values of Index of Association $\bar{r}_{\mathrm{d}}$ (from -0.2 to 0.3 ) corroborates this result. Furthermore, the overall value of $\bar{r}_{\mathrm{d}}=0.014(P=0.083)$ (Fig. 2B) indicative of the outcrossing mode of reproduction, is in agreement with the species biology (Nesom, 2001; Stuessy, 1973, 1977).

With regard to the diversity indices calculated, the selected 17 eSSRs detected from 4 to 15 alleles per locus with a mean of $\approx 8$ (Table 2). The allelic richness ranged from 0.09 to 0.52 , with a high cumulative mean of 0.32 . The observed heterozygosity $(0.26)$ was much lower than the expected heterozygosity $(0.70)$. This was likely derived from the low number of accessions present in this collection, or, given the growth habit, the plants may be relatively inbred. The very low value for Shannon's diversity index (1.17) indicative of generally low allele species richness/evenness and far from saturating the expected species diversity, may have stemmed from the same relatively low sample number in this study. The same limitation also applied to the relatively high values of the eSSR evenness indices, ranging from 0.56 to 0.96 , with a mean of 0.74 . Very high values of the Wright's fixation index $(\mathrm{F})$ implied an excess of homozygosity relative to that expected under the Hardy-Weinberg equillibrium of the varieties of $C$. virginianum, despite rather strong support for the outcrossing mode of this plant reproduction
(Fig. 2B). High gene flow calculated for our C. virginianum collection $(\mathrm{Nm}=1.68)$ likely had a smoothening effect on the allele frequencies, rendering high values of the evenness index. All these characteristics, however, must be taken with caution owing to the limited sampling and, although promising, certainly needs to be confirmed in a largescale study.

Despite the low number of samples included in this study, we achieved reliable separation of some of the $C$. virginianum varieties with DAPC (Fig. 3). Specifically, we observed distant placement of the var. australe from the other varieties, and a possible emergence of an additional new botanical variety, tentatively dubbed 'Ocoee-type'

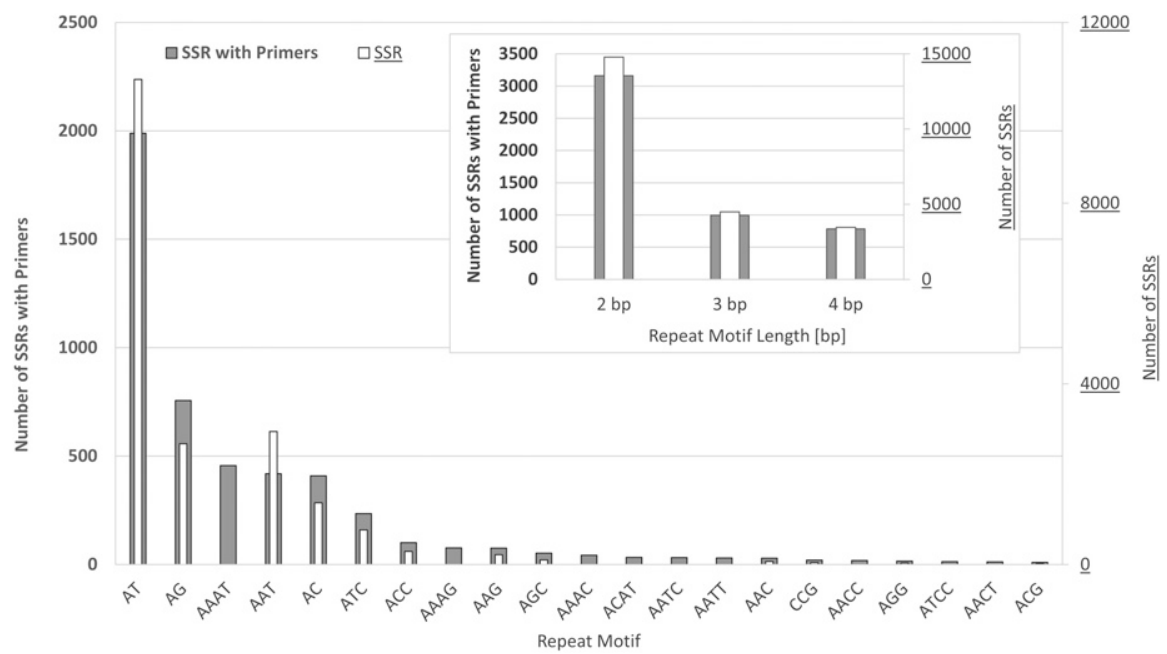

Fig. 1. Genic simple sequence repeats (eSSRs) discovered in the transcriptome of Chrysogonum virginianum 'Chry_2'. Assembled RNA sequencing reads were screened for presence of di-, tri-, and tetra-motif repeat SSRs. Frequency (counts) of top 20 eSSR nonredundant motifs found in the assembled transcriptome are depicted in white; SSRs with primers constructed as per our algorithm are shown in gray. Insert: Frequency (counts) of di-, tri-, and tetra-motif repeat eSSRs. Note: Frequencies of nonredundant tetra-repeat eSSRs were not inspected before devising the primers for them. $b p=b a s e$ pair.
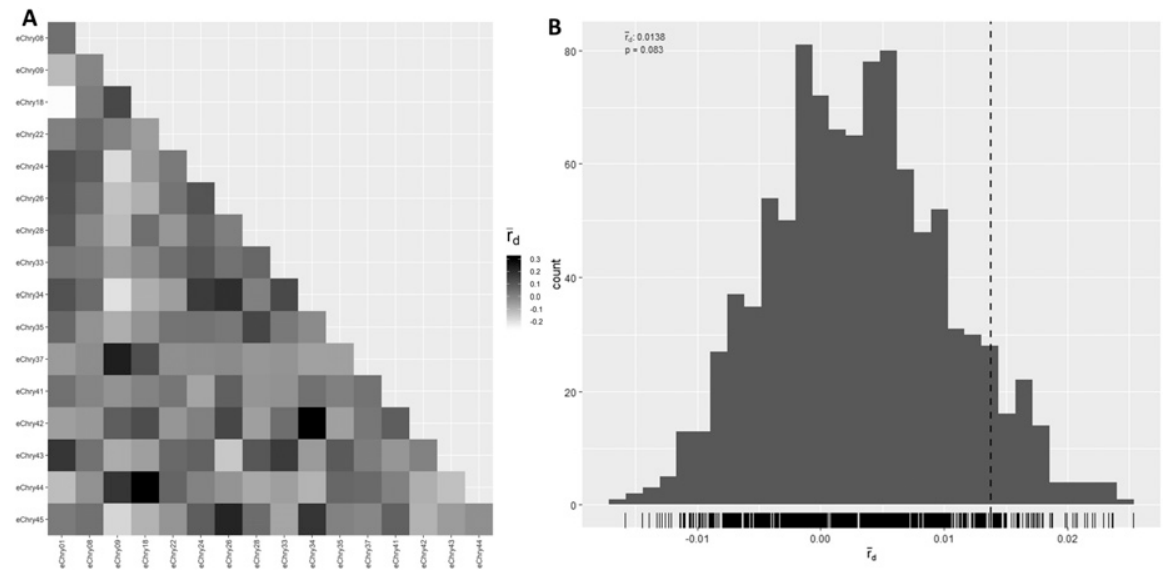

Fig. 2. Linkage disequilibrium of the tested genic simple sequence repeats (eSSRs) of Chrysogonum virginianum. (A) Pairwise Index of Association $\left(\overline{\mathrm{r}}_{d}\right)$ was tested to infer the eSSR distribution over $C$. virginianum genome by the feature of the probability of their cosegregation. The $\overline{\mathrm{r}}_{d}$ values are colorcoded, according to the legend depicted on the right side. (B) Collection-wise $\overline{\mathrm{r}}_{d}$ was inferred over 1000 permutations of the entire dataset $(\mathrm{n}=32)$. The overall $\overline{\mathrm{r}}_{d}$ (black dashed line) and the corresponding $P$ value are denoted. 


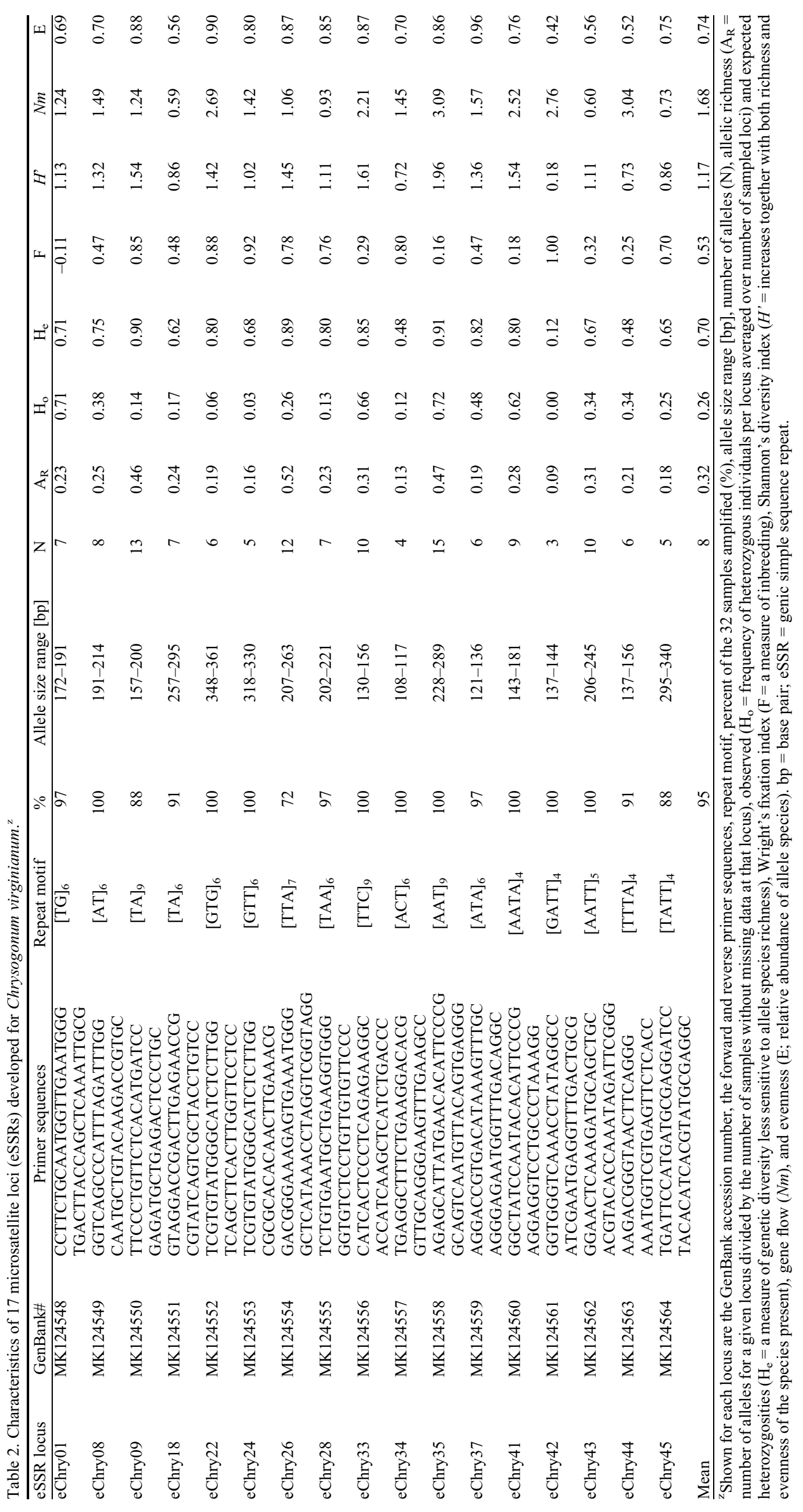




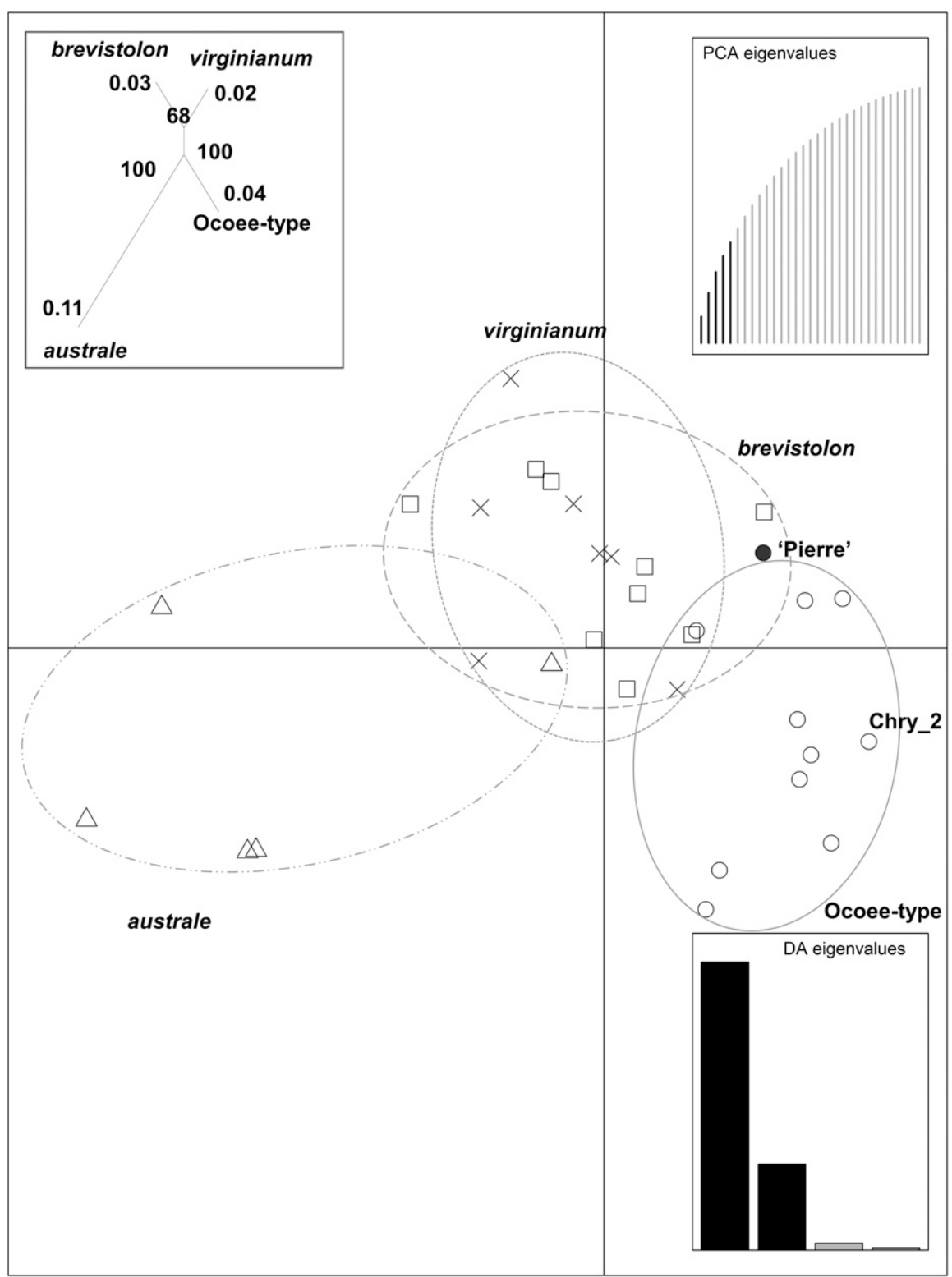

Fig. 3. Discriminant Analysis of Principal Components of the Chrysogonum virginianum genic simple sequence repeat (eSSR) dataset. All samples of $C$. virginianum used in this study are presented, with varieties labeled. The analysis was cross-checked by optimizing the number of principal components used from 1 to 32 (1000 permutations). C. virginianum 'Pierre' was added as a proof of concept for the subspecies placement by eSSR. The specimen 'Chry_2' that was used for the RNA sequencing is marked. (Insert) C. virginianum variety-wise unrooted tree of genetic distances. Samples used in the study were grouped by variety to infer the genetic distances $\left[\mathrm{F}_{\mathrm{ST}}\right]$ among them (here, ranging from 0.02 to 0.11 ). The analysis was permuted 1000 times, and the bootstrap support [\%] of each split is presented. PCA $=$ principal components analysis.

for its place of origin. In contrast, vars. virginianum and brevistolon were not clearly delineated from each other. The morphological difference between typical var. virginianum and var. brevistolon is small, but both herbarium and field observations showed that the geographic boundary is sharply defined (as mapped), thus some kind of genic differentiation should be expected (G.L. Nesom, personal communication). Notably, our observations are tentative in character and need to be tested on a large-scale study, possibly involving auxiliary molecular evidence (e.g., sequencing of chosen informative or "barcoding" loci; CBOL Plant Working Group, 2009), as well as descriptive taxonomy using (Duminil and Di Michele, 2009; Reed and Frankham, 2001). Several reports successfully used the Amplified Fragment Length Polymorphism as molecular markers neutral in character and of nuclear origin, for plant species delimitation (Chen et al., 2013; Meudt et al., 2009; Segatto et al., 2017) or SSR alike (Chen et al., 2013; Dupuis et al., 2012; Meudt et al., 2009). In particular, the eSSR markers may be of interest due to their conservation and informativeness among the closely related species (Ellis and Burke, 2007). SSRs also help increase the power of low taxonomic level distinction in agreement with the "one marker is not enough" approach (Dupuis et al., 2012; the geographical and ecological methods
Segatto et al., 2017). The tentative assignment of the commercial cultivar Pierre to the large cluster with samples of vars. virginianum and brevistolon (which are not distinguished here) serves as proof of concept for such analyses in the $C$. virginianum subspecies complex. Although our collection did not allow for reliable distinction between those two varieties, we postulate that the eSSRs developed in this study can serve such a general purpose. Thus, an investigation using broader sampling of $C$. virginianum specimens may clarify the taxonomic classification of the genus at the lowest ranks (Nesom, 2001; Stuessy, 1973, 1977). In addition, this might lead to changes of varietal circumscriptions (Clausen et al., 1939; Duminil and Di Michele, 2009; Lowry, 2012).

In conclusion, our de novo eSSR markers provide a material progress in the analyses of C. virginianum complex in several aspects. As exemplified with the analyzed collection, the eSSRs can be used for species diversity studies, including conservation research. By applying the eSSR genotyping and downstream analyses, we achieved reliable separation of the Chrysogonum varieties, confirmed the molecular distinction of a tentative new variety, and postulated an enhanced separation for the vars. virginianum and brevistolon Finally, as demonstrated for the commercial cultivar Pierre, the eSSRs can be used for enhancing the future breeding or hybridization efforts of this ornamental plant.

\section{Literature Cited}

Abu-Asab, M.S., P.M. Peterson, S.G. Shetler, and S.S. Orli. 2001. Earlier plant flowering in spring as a response to global warming in the Washington, DC, area. Biodivers. Conserv. 10: 597-612.

Amos, W., J. Hoffman, A. Frodsham, L. Zhang, S. Best, and A. Hill. 2007. Automated binning of microsatellite alleles: Problems and solutions. Mol. Ecol. Resour. 7:10-14.

Andrews, S. 2014. FastQC: A quality control tool for high throughput sequence data. Version 0.11.2. Babraham Institute, Cambridge, UK. 1 Nov. 2018. <http://www.bioinformatics. babraham.ac.uk/projects/fastqc $>$.

Archer, F.I., P.E. Adams, and B.B. Schneiders 2017. stratag: An R package for manipulating, summarizing and analysing population genetic data. Mol. Ecol. Resour. 17:5-11.

Arias, R.S., N. Techen, T.A. Rinehart, R.T. Olsen, J.H. Kirkbride, and B.E. Scheffler. 2011. Development of simple sequence repeat markers for Chionanthus retusus (Oleaceae) and effective discrimination of closely related taxa. HortScience 46:23-29.

CBOL Plant Working Group. 2009. A DNA barcode for land plants. Proc. Natl. Acad. Sci. USA 106:12794-12797.

Chen, X., M. Sun, J. Liang, H. Xue, and Q. Zhang. 2013. Genetic diversity of species of Chrysanthemum and related genera and groundcover cultivars assessed by amplified fragment length polymorphic markers. HortScience 48:539546.

Clausen, J., D.D. Keck, and W.M. Hiesey. 1939. The concept of species based on experiment. Amer. J. Bot. 26:103-106.

Clevinger, J.A. and J.L. Panero. 2000. Phylogenetic analysis of Silphium and subtribe Engelmanniinae 
(Asteraceae: Heliantheae) based on ITS and ETS sequence data. Amer. J. Bot. 87:565572 .

Duminil, J. and M. Di Michele. 2009. Plant species delimitation: A comparison of morphological and molecular markers. Plant Biosyst. 143: 528-542.

Dupuis, J.R., A.D. Roe, and F.A. Sperling. 2012. Multi-locus species delimitation in closely related animals and fungi: One marker is not enough. Mol. Ecol. 21:4422-4436.

Ellis, J. and J. Burke. 2007. EST-SSRs as a resource for population genetic analyses. Heredity 99 : $125-132$.

Esfandani Bozchaloyi, S., M. Sheidai, M. Keshavarzi, and Z. Noormohammadi. 2017. Species delimitation in Geranium sect. Batrachioidea: Morphological and molecular. Acta Bot. Hung. 59:319-334.

Eujayl, I., M. Sorrells, M. Baum, P. Wolters, and W. Powell. 2001. Assessment of genotypic variation among cultivated durum wheat based on EST-SSRs and genomic SSRs. Euphytica 119:39-43.

Gaddy, L. 1986. Twelve new ant-dispersed species from the southern Appalachians. Bull. Torrey Bot. Club 113:247-251.

Goudet, J. 2005. Hierfstat, a package for R to compute and test hierarchical F-statistics. Mol. Ecol. Resour. 5:184-186.

Goudet, J., M. Raymond, T. de Meeüs, and F. Rousset. 1996. Testing differentiation in diploid populations. Genetics 144:1933-1940.

Gray, A. 1882. Chrysogonum virginianum, var. dentatum. Bot. Gaz. 7:31-32.

Hawks, K.T. 2008. Chrysogonum plant named 'Quinn's Gold'. U.S. Patent Application 11/ 906,656, filed 7 Oct. 2008.

Hoffman, M.H.A., M.E.C.M. Hop, and F.A.M. Geers. 2005. List of names of perennials, section Trees. International Standard 20052010. Applied Plant Research, Lisse, The Netherlands.

Jiang, H., R. Lei, S.-W. Ding, and S. Zhu. 2014. Skewer: A fast and accurate adapter trimmer for next-generation sequencing paired-end reads. BMC Bioinformatics 15:182.

Jombart, T., S. Devillard, and F. Balloux. 2010. Discriminant analysis of principal components: A new method for the analysis of genetically structured populations. BMC Genet. 11:94.
Jombart, T., Z.N. Kamvar, C. Collins, R. Lustrik, M.-P. Beugin, B.J. Knaus, and M.T. Jombart. 2018. Package 'adegenet'. Github repository: $<$ https://github.com/thibautjombart/adegenet $>$.

Kamvar, Z.N., J.C. Brooks, and N.J. Grünwald. 2015. Novel R tools for analysis of genomewide population genetic data with emphasis on clonality. Front. Genet. 6:208.

Kamvar, Z.N., J.F. Tabima, and N.J. Grünwald. 2014. Poppr: An R package for genetic analysis of populations with clonal, partially clonal, and/or sexual reproduction. PeerJ 2:e281.

Linnaeus, C. 1754. Genera plantarum, exhibentes, p. 391. 5th ed. Salvius, Stockholm.

Lowry, D.B. 2012. Ecotypes and the controversy over stages in the formation of new species. Biol. J. Linn. Soc. Lond. 106:241-257.

Meudt, H.M., P.J. Lockhart, and D. Bryant. 2009. Species delimitation and phylogeny of a New Zealand plant species radiation. BMC Evol. Biol. 9:111.

Morgulis, A., E.M. Gertz, A.A. Schäffer, and R. Agarwala. 2006. A fast and symmetric DUST implementation to mask low-complexity DNA sequences. J. Comput. Biol. 13:1028-1040.

Nesom, G. 1978. Myrmecochory in Chrysogonum virginianum L. (Compositae). Bot. Soc. Amer. Abstr. Misc. Ser. Publ 156:21.

Nesom, G. 2001. Taxonomic review of Chrysogonum (Asteraceae: Heliantheae). SIDA Contrib. Bot. 19:811-820.

Panero, J.L. and R.K. Jansen. 1997. Chloroplast DNA restriction site study of Verbesina (Asteraceae: Heliantheae). Amer. J. Bot. 84:382-392.

Panero, J.L., R.K. Jansen, and J.A. Clevinger. 1999. Phylogenetic relationships of subtribe Ecliptinae (Asteraceae: Heliantheae) based on chloroplast DNA restriction site data. Amer. J. Bot. 86:413-427.

Peakall, R. and P.E. Smouse. 2012. GenAlEx 6.5: Genetic analysis in Excel. Population genetic software for teaching and research — an update. Bioinformatics 28:2537-2539.

Peng, Y., X. Gao, R. Li, and G. Cao. 2014. Transcriptome sequencing and de novo analysis of Youngia japonica using the Illumina platform. PLoS One 9:e90636.

Reed, D.H. and R. Frankham. 2001. How closely correlated are molecular and quantitative measures of genetic variation? A meta-analysis. Evolution 55:1095-1103.
Segatto, A.L.A., M. Reck-Kortmann, C. Turchetto, and L.B. Freitas. 2017. Multiple markers, niche modelling, and bioregions analyses to evaluate the genetic diversity of a plant species complex. BMC Evol. Biol. 17:234.

Simpson, J.T., K. Wong, S.D. Jackman, J.E. Schein, S.J. Jones, and I. Birol. 2009. ABySS: A parallel assembler for short read sequence data. Genome Res. 19:1117-1123.

Solbrig, O.T., D.W. Kyhos, M. Powell, and P.H. Raven. 1972. Chromosome numbers in Compositae VIII: Heliantheae. Amer. J. Bot. 59: 869-878.

Staton, M.E. and S. Ficklin. 2018. Finding SSRs findssrs_altered.pl, Github repository: $<$ https:// github.com/statonlab/Finding-SSRs $>$.

Stuessy, T.F. 1973. A systematic review of the subtribe Melampodiinae (Compositae, Heliantheae). Contr. Gray Herb. 203:65-80.

Stuessy, T.F. 1977. Revision of Chrysogonum (Compositae, Heliantheae). Rhodora 79:190-202.

The R Core Team. 2014. R: A language and environment for statistical computing. R Foundation for Statistical Computing, Vienna, Austria.

Trigiano, R., S. Boggess, and E. Bernard. 2018a. First report of powdery mildew caused by Golovinomyces spadiceus on Green and Gold (Chrysogonum virginianum) in the United States. Plant Dis. 102:252.

Trigiano, R., S. Boggess, and B. Ownley. 2018 b. First report of an aerial blight of Chrysogonum virginianum (Green and Gold) caused by Sclerotinia sclerotiorum in the United States. Plant Dis. 102:450.

Untergasser, A., I. Cutcutache, T. Koressaar, J. Ye, B.C. Faircloth, M. Remm, and S.G. Rozen. 2012. Primer3 - new capabilities and interfaces. Nucleic Acids Res. 40:e115.

Varshney, R.K., A. Graner, and M.E. Sorrells. 2005. Genic microsatellite markers in plants: Features and applications. Trends Biotechnol. 23:48-55.

Varshney, R.K., T. Thiel, N. Stein, P. Langridge, and A. Graner. 2002. In silico analysis on frequency and distribution of microsatellites in ESTs of some cereal species. Cell. Mol. Biol. Lett. 7:537-546.

Weakley, A.S. 2015. Flora of the southern and midAtlantic states. University of North Carolina Herbarium, North Carolina Botanical Garden, University of North Carolina, Chapel Hill. 